\title{
Antibiotic prophylaxis for patients with prenatal hydronephrosis and vesicoureteral reflux (VUR): No one recipe for all
}

\author{
Julie Franc-Guimond, MD \\ Division of Pediatric Urology, CHU Sainte-Justine; Department of Surgery, University of Montreal, Montreal, QC, Canada
}

Cite as: Can Urol Assoc J 2017;11 (1-2Suppl1):S25. http://dx.doi.org/10.5489/cuaj.4388

See related article on page $S 20$.

W riting a review on a rather controversial topic is not a simple task. The authors certainly managed to address the subject in a very structured and most certainly useful manner. But despite a well-thoughtout overview of the use of continuous antibiotic prophylaxis (CAP) in the setting of prenatal hydronephrosis $(\mathrm{HN})$ and vesicoureteral reflux (VUR), uncertainties remain.

I too wish to stress that it remains difficult, read impossible, to put all the patients in the same category and offer one recipe for all. Hence, an individualized approach should always be used. If only we could figure out how to make sure to investigate, care, and perhaps surgically correct anatomical anomalies of some patients while disregarding, to some extent, the urological realities of others... things would be much simpler. But we have yet to do so.
Therefore, we must look at the big picture and keep in mind that polemics lie at various levels: limit the risk of doing unnecessary tests vs. risk of missing significant urological anomalies, prevent or limit renal scarring vs. risk of renal impairment, and consider or not the use of CAP to prevent urinary tract infections (UTIs).

As mentioned in the review, we ought to make decisions based on many variables, but most importantly, we need to take the time to sit down with a patient and his/her family and discuss options, risks, and likely outcomes. We need to take the time.

Competing interests: The author reports no competing personal or financial interests.

This paper has been peer-reviewed.

Correspondence: Dr. Julie Franc-Guimond, Division of Pediatric Urology, CHU Sainte-Justine; Department of Surgery, University of Montreal, Montreal, QC, Canada; julie.franc-guimond.hsj@ssss.gouv.qc.ca 